\title{
Mechanisms underlying the recovery of lower urinary tract function following spinal cord injury*
}

\author{
WC de Groat \\ Professor of Pharmacology and Neuroscience, University of Pittsburgh, School of Medicine, W1352 Biomedical \\ Science Tower, Pittsburgh, PA 15261, USA
}

Keywords: neurourology; urinary bladder; neuroplasticity; automatic micturition; spinal cord injury

\section{Introduction}

The functions of the lower urinary tract to store and periodically release urine are dependent upon neural circuits located in the brain, spinal cord and peripheral ganglia. ${ }^{1,2}$ This dependence on central nervous control distinguishes the lower urinary tract from many other visceral structures (eg the gastrointestinal tract and cardiovascular system) that maintain a certain level of function even after elimination of extrinsic neural input.

The lower urinary tract is also unusual in regard to its pattern of activity and the complexity of its neural regulation. For example, the urinary bladder has two principal modes of operation: storage and elimination. Thus many of the neural circuits exhibit switch-like or phasic patterns of activity ${ }^{3}$ in contrast to tonic patterns occurring in autonomic pathways to cardiovascular organs. In addition, micturition is under voluntary control and depends upon learned behavior which develops during maturation of the nervous system; whereas many other visceral functions are regulated involuntarily. Micturition also depends on the integration of autonomic and somatic efferent mechanisms within the lumbosacral spinal cord. ${ }^{4}$ This is necessary during urine storage and elimination to coordinate the activity of visceral organs (the bladder and urethra) with that of urethral striated muscles.

The dependence of lower urinary tract functions on complex central neural networks renders these functions susceptible to a variety of neurological disorders. ${ }^{4,5}$ This paper will review studies in animals and humans that have provided insights into the neural control of the lower urinary tract and the disruption of this control by spinal cord injury.

\section{Anatomy and innervation}

The storage and periodic elimination of urine are regulated by the activity of two functional units in the

\footnotetext{
*The Sir Ludwig Guttmann Lecture given at the Annual Scientif Meeting of the International Medical Society of Paraplegia, Ghent, Belgium, 27 May 1993
}

lower urinary tract: (1) a reservoir (the bladder) and (2) an outlet (consisting of bladder neck, urethra, and striated muscles of the pelvic floor). Under normal conditions, the urinary bladder and outlet exhibit a reciprocal relationship. During urine storage, the bladder neck and proximal urethra are closed; and the bladder smooth muscle is quiescent, allowing the intravesical pressure to remain low over a wide range of bladder volumes. During voluntary micturition the initial event is a reduction of intraurethral pressure, which reflects a relaxation of the pelvic floor and the paraurethral striated muscles and an opening of the bladder neck. ${ }^{4,5}$ These changes in the urethra are followed in a few seconds by a detrusor contraction and a rise in intravesical pressure which is maintained until the bladder empties. Reflex inhibition of the smooth and striated muscles of the urethra also contribute to the reduction of outlet resistance during micturition.

These changes are coordinated by three sets of nerves emerging from the thoracolumbar and sacral levels of the spinal cord: (1) sacral parasympathetic (pelvic nerves), (2) sacral somatic (pudendal nerves) and (3) thoracolumbar sympathetic (hypogastric nerves and sympathetic chain) (Figure 1). ${ }^{1-8}$ The sacral parasympathetic efferent pathway provides the major excitatory input to the bladder and consists of spinal preganglionic neurons which send axons to peripheral ganglion cells which in turn innervate the bladder smooth muscle (Figure 1). Transmission in bladder ganglia is mediated by nicotinic cholinergic receptors; whereas excitatory input to the bladder smooth muscle is mediated by acetylcholine acting on muscarinic receptors and by a cotransmitter adenosine triphosphate (ATP) acting on $\mathrm{P}_{2}$ purinergic receptors (Table 1). ${ }^{9}$

Cholinergic transmission at both the ganglionic and postganglionic level is modulated by a variety of transmitter mechanisms. ${ }^{2}$ For example ganglionic synapses are regulated by muscarinic, adrenergic, purinergic, and enkephalinergic mechanisms (Table 1). Postganglionic transmission in the bladder is also controlled presynaptically by transmitters which regulate acetylcholine release. ${ }^{10-13}$ The most prominent presynaptic 


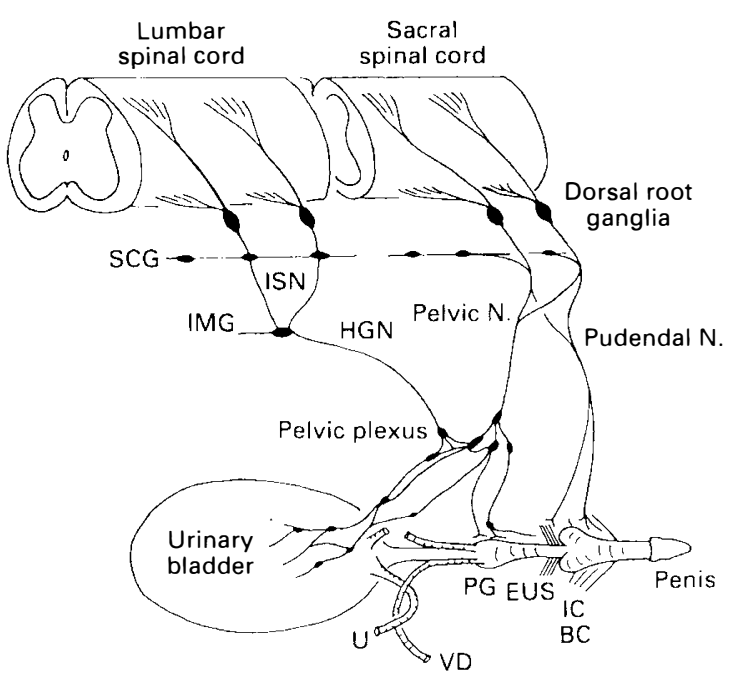

Figure 1 Diagram showing the sympathetic, parasympathetic, and somatic innervation of the urogenital tract of the male cat. Sympathetic preganglionic pathways emerge from the lumbar spinal cord and pass to the sympathetic chain ganglia (SCG) and then via the inferior splanchnic nerves (ISN) to the inferior mesenteric ganglia (IMG). Preganglionic and postganglionic sympathetic axons then travel in the hypogastric nerve (HGN) to the pelvic plexus and the urogenital organs. Parasympathetic preganglionic axons which originate in the sacral spinal cord pass in the pelvic nerve to ganglion cells in the pelvic plexus and to distal ganglia in the organs. Sacral somatic pathways are contained in the pudendal nerve, which provides an innervation to the penis, the ischiocavernosus (IC), bulbocavernosus (BC), and external urethral sphincter (EUS) muscles. The pudendal and pelvic nerves also receive postganglionic axons from the caudal sympathetic chain ganglia. These three sets of nerves contain afferent axons from the lumbosacral dorsal root ganglia. U: ureter; PG: prostate gland; VD: vas deferens; Reproduced from de Groat, $1992^{8}$ with permission modulation is mediated by $\mathrm{M}-1$ muscarinic autoreceptors which are activated during high frequency nerve firing and markedly facilitate acetylcholine release. ${ }^{10,11}$ Thus, peripheral cholinergic synapses exhibit a considerable degree of plasticity which is determined by the intensity and/or pattern of neural activity. This plasticity no doubt plays an important role in urine storage as well as in promoting complete emptying of the bladder.

Somatic efferent pathways to the external urethral sphincter are cholinergic and are carried in the pudendal nerve from anterior horn cells in the third and fourth sacral segments. Branches of the pudendal nerve and other sacral somatic nerves also carry efferent impulses to muscles of the pelvic floor.

Sympathetic preganglionic pathways that arise from the T11 to L2 spinal segments pass to the sympathetic chain ganglia and then to prevertebral ganglia in the superior hypogastric and pelvic plexuses and also to short adrenergic neurons in the bladder and urethra. Sympathetic postganglionic nerves which release norepinephrine provide an excitatory input to smooth muscle of the urethra and bladder base, an inhibitory input to smooth muscle in the body of the bladder, as well as inhibitory and facilitatory input to vesical parasympathetic ganglia. ${ }^{1,2,5}$ The adrenergic receptors mediating these responses are listed in Table 1.

Other putative transmitters including neuropeptide Y (NPY), vasoactive intestinal polypeptide (VIP) and nitric oxide have also been identified in efferent pathways to the lower urinary tract of animals and humans (Table 1). NPY is present in adrenergic and cholinergic neurons and when administered exogenously has a prejunctional inhibitory action to suppress the release of norepinephrine and acetylcholine from postganglionic nerve terminals. ${ }^{12}$ Nitric oxide and VIP have smooth muscle relaxant effects. Nitric oxide has been identified as the parasympathetic transmitter

Table 1 Receptors for putative transmitters in the lower urinary tract

\begin{tabular}{llll}
\hline Tissue & Cholinergic & Adrenergic & Other \\
\hline Bladder body & $+(\mathrm{M} 2)$ & $-\left(\beta_{2}\right)$ & + Purinergic $\left(\mathrm{P}_{2}\right)$ \\
& $+(\mathrm{M} 3)$ & $+\left(\alpha_{1}\right)$ & - VIP \\
& $+(\mathrm{M} 1)^{\mathrm{a}}$ & $+\left(\alpha_{1}\right)^{\mathrm{a}}$ & + Substance $\mathrm{P}$ \\
& & & - Neuropeptide Ya \\
Bladder base & $+(\mathrm{M} 2)$ & $+\left(\alpha_{1}\right)$ & - VIP \\
& $+(\mathrm{M} 3)$ & - Neuropeptide Ya \\
Ganglia & $+(\mathrm{N})$ & $+\left(\alpha_{1}\right)$ & - Enkephalinergic $(\delta)$ \\
& $+(\mathrm{M} 1)$ & $-\left(\alpha_{2}\right)$ & - Purinergic $\left(\mathrm{P}_{1}\right)$ \\
Urethra & $+(\mathrm{M})$ & $+(\beta)$ & + Substance $\mathrm{P}$ \\
& & $+\left(\alpha_{1}\right)$ & + Purinergic $\left(\mathrm{P}_{2}\right)$ \\
& & $+\left(\alpha_{2}\right)$ & - VIP \\
Sphincter striated muscle & $-\left(\beta_{2}\right)$ & - Neuropeptide $\mathrm{Y}^{\mathrm{a}}$
\end{tabular}

Letters in parentheses indicate receptor type, $\mathrm{M}$ (muscarinic) and $\mathrm{N}$ (nicotinic)

+ and - indicate excitatory and inhibitory effects. aindicates presynaptic receptors on nerve terminals that control transmitter release 
mediating relaxation of the urethral smooth muscle. ${ }^{9,13}$

Afferent activity arising in the bladder is conveyed to the central nervous system over both sets of autonomic nerves. ${ }^{1,5.14-19}$ The most important afferents for initiating micturition are those passing in the pelvic nerves to the sacral spinal cord. These afferents consist of small myelinated (A $\delta$ ) and unmyelinated (C) fibers which convey impulses from tension receptors and nociceptors in the bladder wall. Electrophysiological studies in the cat have shown that $\mathrm{A} \delta$ bladder afferents respond in a graded manner to passive distension as well as active contraction of the bladder. ${ }^{5,14}$ The intravesical pressure threshold for activation of these afferents ranges from 5 to $15 \mathrm{~mm} \mathrm{Hg}$ which is consistent with pressures at which humans report the first sensation of bladder filling during cystometry.

High threshold C-fiber afferents have also been detected in the cat bladder. ${ }^{15,16}$ Under normal conditions the large majority of these afferents do not respond to bladder distension and therefore have been termed 'silent C-fibers'; however many of these fibers can be activated by chemical irritation of the bladder mucosa ${ }^{15,16}$ or cold temperatures. ${ }^{20}$ Following chemical irritation, the C-fiber afferents exhibit spontaneous firing when the bladder is empty and increased firing during bladder distension. ${ }^{15,16}$ Activation of C-fiber afferents by chemical irritation facilitates the micturition reflex and decreases bladder capacity.,17,21 Administration of capsaicin, a neurotoxin which desensitizes $\mathrm{C}$-fiber afferents, blocks the bladder hyperactivity induced by noxious stimuli; but does not block micturition reflexes in normal animals indicating that C-fiber afferent pathways are not essential for normal voiding. ${ }^{1,17,22-24}$

Immunohistochemical studies have shown that a large percentage of bladder afferent neurons contain peptides: calcitonin-gene-related-peptide (CGRP), vasoactive intestinal polypeptide (VIP) substance $P$, enkephalins and cholecystokinin (CCK). ${ }^{1,18,25}$ In the spinal cord, peptidergic nerve terminals have a distribution very similar to the distribution of bladder afferents (Figure 2). ${ }^{19,26}$ In the bladder, these peptides are also common in nerves in the submucosal and subepithelial layers, and around blood vessels. The neurotoxin, capsaicin, when applied locally to the bladder in experimental animals releases peptides from peripheral afferent terminals and produces inflammatory responses, including plasma extravasation and vasodilation. ${ }^{17}$ These findings suggest that the neuropeptides may be important transmitters in afferent pathways in the lower urinary tract.

\section{Reflex mechanisms controlling the lower urinary tract}

The central pathways controlling lower urinary tract function are organized as simple on-off switching circuits (Figure 3) which maintain a reciprocal relationship between the urinary bladder and the urethral outlet. The principal reflex components of these
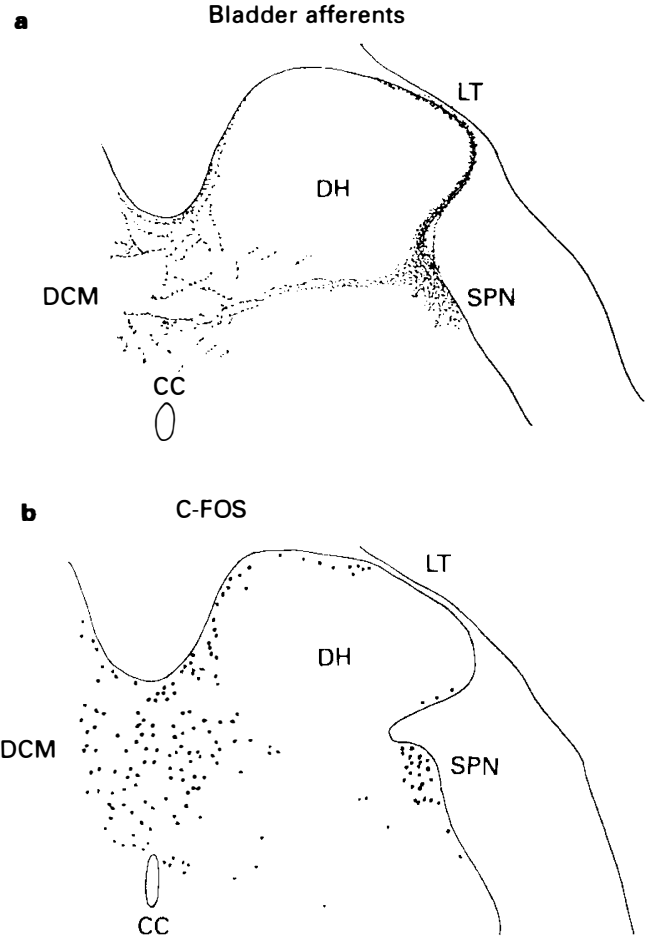

Figure 2 Comparison of the distribution of bladder afferent projections to the L6 spinal cord of the rat (A) with the distribution of $c$-fos positive cells in the L6 spinal segment following chemical irritation of the lower urinary tract of the rat (B). Afferents labelled by WGA-HRP injected into the urinary bladder. $C$-fos immunoreactivity is present in the nuclei of cells. DH: dorsal horn; SPN: sacral parasympathetic nucleus; CC: central canal. Calibration represents $500 \mu \mathrm{m}$

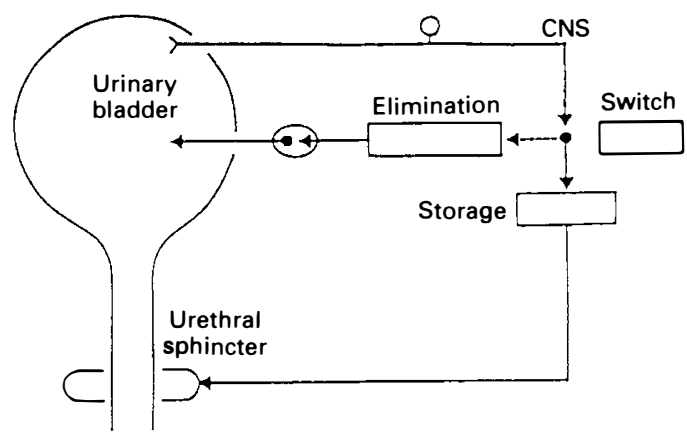

Figure 3 Diagram illustrating the anatomy of the lower urinary tract and the switchlike function of the micturition reflex pathway. During urine storage, a low level of afferent activity activates efferent input to the urethral sphincter. A high level of afferent activity induced by bladder distention activates the switching circuit in the central nervous system (CNS), producing firing in the efferent pathways to the bladder, inhibition of the efferent outflow to the sphincter, and urine elimination

switching circuits are listed in Table 2 and are illustrated in Figure 4. Intravesical pressure measurements during bladder filling in both man and animals reveal low and relatively constant bladder pressures when the 
Table 2 Reflexes to the lower urinary tract

\begin{tabular}{lll}
\hline Afferent pathway & Efferent pathway & Central pathway \\
\hline Urine storage & 1 External sphincter contraction (somatic nerves) & Spinal reflexes \\
$\quad$ Low level vesical afferent activity & 2 Internal sphincter contraction (sympathetic nerves) & \\
$\quad 3$ (pelvic nerve) & 3 Detrusor inhibition (sympathetic nerves) & \\
& 4 Ganglionic inhibition (sympathetic nerves) & Spinobulbospinal reflexes \\
& 5 Sacral parasympathetic outflow inactive & \\
$\begin{array}{l}\text { Micturition } \\
\quad \text { High level vesical afferent activity }\end{array} \quad$ Inhibition of external sphincter activity & \\
$\quad$ (pelvic nerve) & 3 Anhibition of sympathetic outflow & \\
\hline
\end{tabular}
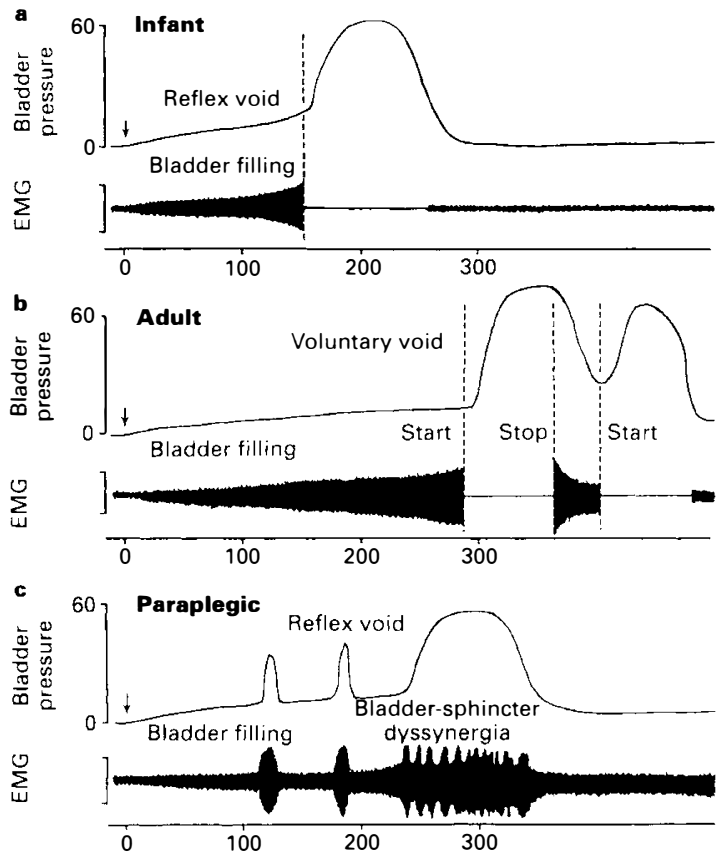

Figure 4 Combined cystometrograms and sphincter electromyograms (EMG) comparing reflex voiding responses in an infant (A) and in a paraplegic patient (C) with a voluntary voiding response in an adult (B). The abscissa in all records represents bladder volume in milliliters and the ordinates represent bladder pressure in $\mathrm{cm} \mathrm{H}_{2} \mathrm{O}$ and electrical activity of the EMG recording. On the left side of each trace the arrows indicate the start of a slow infusion of fluid into the bladder (bladder filling). Vertical dashed lines indicate the start of sphincter relaxation which precedes by a few seconds the bladder contraction in A and B. In part $B$ note that a voluntary cessation of voiding (stop) is associated with an initial increase in sphincter EMG followed by a reciprocal relaxation of the bladder. A resumption of voiding is again associated with sphincter relaxation and a delayed increase in bladder pressure. On the other hand, in the paraplegic patient $(\mathrm{C})$ the reciprocal relationship between bladder and sphincter is abolished. During bladder filling, transient uninhibited bladder contractions occur in association with sphincter activity. Further filling leads to more prolonged and simultaneous contractions of the bladder and sphincter (bladder-sphincter dyssynergia). Loss of the reciprocal relationship between bladder and sphincter in paraplegic patients interferes with bladder emptying. Reproduced from de Groat and Steers, $1990^{7}$ with permission bladder volume is below the threshold for inducing voiding (Figure 4A). The accommodation of the bladder to increasing volumes of urine is primarily a passive phenomenon dependent upon the intrinsic properties of the vesical smooth muscle and quiescence of the parasympathetic efferent pathway. ${ }^{1,4,5}$ In addition, in some species urine storage is also facilitated by sympathetic reflexes which mediate an inhibition of bladder activity, closure of the bladder neck and contraction of the proximal urethra (Table 2, Figure 5). During bladder filling the activity of the sphincter electromyogram (EMG) also increases (Figure 4B), reflecting an increase in efferent firing in the pudendal nerve and an increase in outlet resistance which contributes to the maintenance of urinary continence.

The storage phase of the urinary bladder can be switched to the voiding phase either involuntarily (reflexly) or voluntarily (Figure 4B). The former is readily demonstrated in the human infant (Figure 4A) or in the anesthetized animal when the volume of urine exceeds the micturition threshold. At this point, increased afferent firing from tension receptors in the bladder reverses the pattern of efferent outflow, producing firing in the sacral parasympathetic pathways and inhibition of sympathetic and somatic pathways. The expulsion phase consists of an initial relaxation of the urethral sphincter (Figure 4A) followed in a few seconds by a contraction of the bladder, an increase in bladder pressure and flow of urine. Secondary reflexes elicited by a flow of urine through the urethra facilitate bladder emptying. 5,27

These reflexes require the integrative action of neuronal populations at various levels of the neuraxis (Figures 5 and 6). Certain reflexes, for example, those mediating the excitatory outflow to the sphincters and the sympathetic inhibitory outflow to the bladder, are organized at the spinal level (Figure 5), whereas the parasympathetic outflow to the detrusor has a more complicated central organization involving spinal and spinobulbospinal pathways (Figure 6).

\section{Anatomy of spinal reflex circuits}

The spinal circuitry controlling the lower urinary tract consists of three basic components: efferent neurons, interneurons and primary afferent neurons. New research methodology including transneuronal virus 


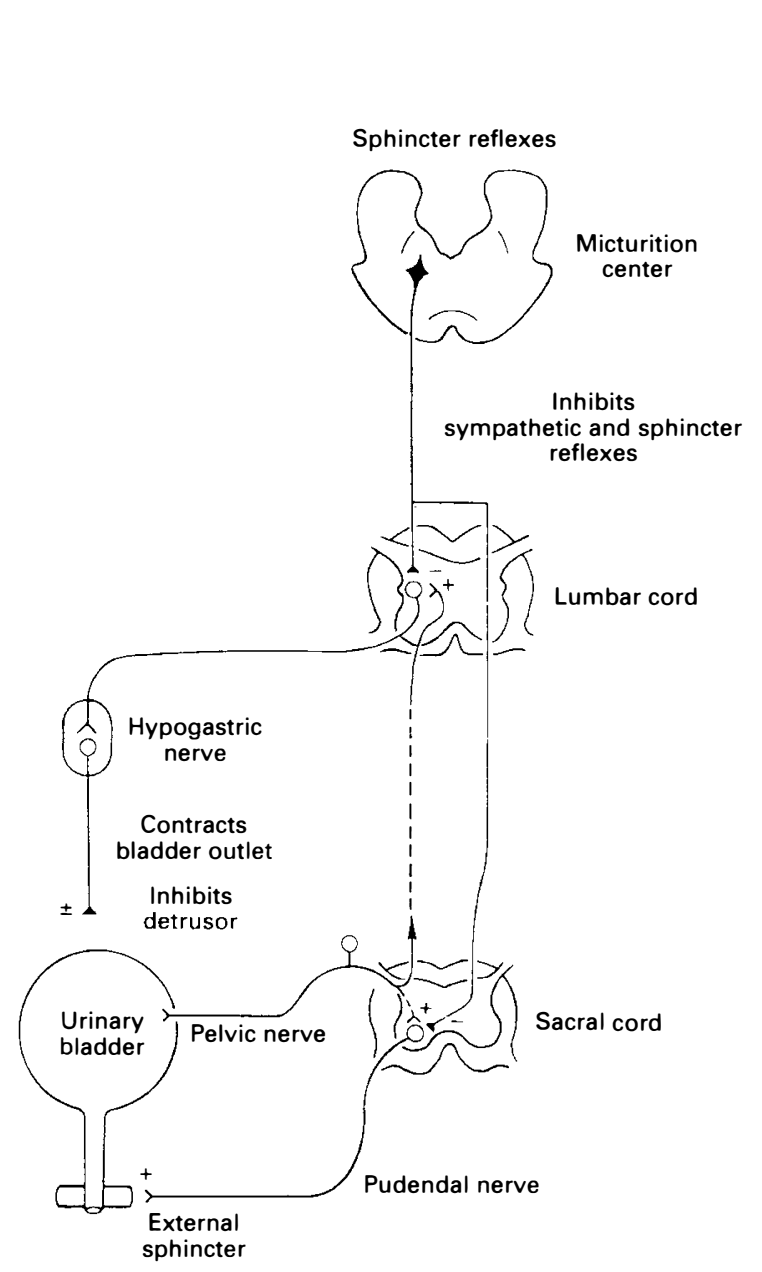

Figure 5 Diagram showing detrusor-sphincter reflexes. During the storage of urine, distention of the bladder produces low level vesical afferent firing, which in turn stimulates (1) the sympathetic outflow to the bladder outlet (base and urethra) and (2) pudendal outflow to the external urethral sphincter. These responses occur by spinal reflex pathways and represent 'guarding reflexes', which promote continence. Sympathetic firing also inhibits detrusor muscle and transmission in bladder ganglia. At the initiation of micturition, intense vesical afferent activity activates the brainstem micturition center, which inhibits the spinal guarding reflexes

tracing, intracellular labelling, measurements of gene expression and patch clamp recording in spinal cord slice preparations have recently provided many new insights into the morphological and electrophysiological properties of these reflex components.

\section{Preganglionic neurons}

Preganglionic neurons in the lumbosacral parasympathetic nucleus send dendrites to discrete regions of the spinal cord including: (1) the lateral and dorsal lateral funiculus, (2) lamina I on the lateral edge of the dorsal horn, (3) the dorsal grey commissure and (4) grey matter and lateral funiculus ventral to the autonomic nucleus. ${ }^{1,28}$ As shown in Figure 7 the cells have long, relatively unbranched dendrites that can extend for distances of $1.5-2 \mathrm{~mm}$ in both the grey and white matter. ${ }^{28}$

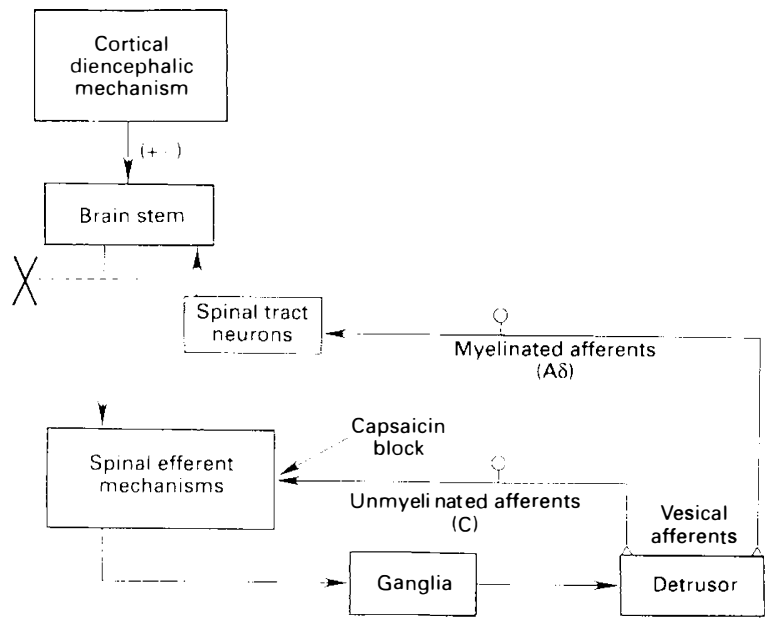

Figure 6 Diagram of the central reflex pathways that regulate micturition in the cat. In an animal with an intact neuraxis, micturition is initiated by a supraspinal reflex pathway passing through a center in the brainstem. The pathway is triggered by myelinated afferents (A $\delta$ ) connected to tension receptors in the bladder wall. In spinal animals, connections between the brainstem and the sacral spinal cord are interrupted (X) and micturition is initially blocked. In chronic spinal animals, however a spinal reflex mechanism emerges which is triggered by unmyelinated (C-fiber) vesical afferents. The C-fiber reflex pathway is usually weak or undetectable in animals with an intact nervous system. Capsaicin $\left(20-30 \mathrm{mg} \mathrm{Kg}^{-1}\right.$ s.c.) blocks the C-fiber reflex in chronic cats, but does not block micturition reflexes in intact cats. Reproduced from de Groat et al, $1990^{23}$ with permission

An unusual feature of sacral preganglionic neurons in the cat is an extensive axon collateral system which projects bilaterally to various regions of the dorsal and ventral horns, including: the area around the central canal; the intermediolateral region of the sacral parasympathetic nucleus, the dorsal commissure and lateral dorsal horn. ${ }^{29}$ It has been speculated that these collaterals mediate intraspinal integrative actions of preganglionic neurons including recurrent inhibition and modulation of sphincter reflexes.

\section{Sphincter motoneurons}

Retrograde axonal tracing has identified pudendal motoneurons and a subpopulation of these neurons innervating the external urethral sphincter (EUS) ${ }^{1,5,30-32}$ In the cat EUS motoneurons are located in the ventrolateral division of Onuf's nucleus and send dendritic projections into: (1) the lateral funiculus, (2) lamina $X,(3)$ intermediolateral grey matter and (4) rostrocaudally within the nucleus (Figure 7). The dentrites occur in bundles passing through restricted regions of the spinal cord. Thus the dendritic distribution of sphincter motoneurons (ie lateral, dorsolateral and dorsomedial) is similar to that of sacral preganglionic neurons indicating that these two populations of neurons may receive synaptic inputs from the same interneuronal pathways and fiber tracts in the spinal cord. 


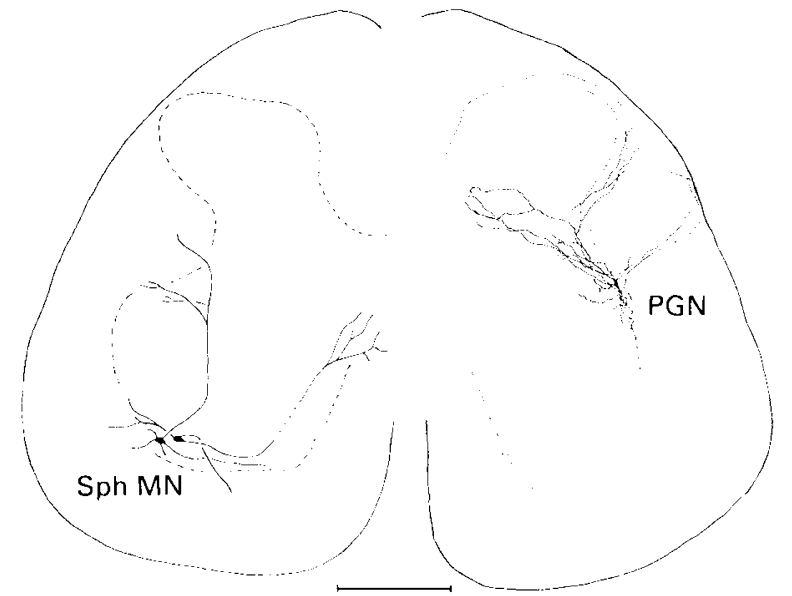

Figure 7 Comparison of the dendritic distributions of external urethral sphincter motoneurons (left side) and a sacral parasympathetic preganglionic neuron (right side) in the cat. The sacral preganglionic neuron which was filled intracellularly with neurobiotin exhibits dendrites which extend into: (1) the lateral funiculus, (2) lateral lamina I, (3) the dorsal commissure and (4) within the sacral autonomic nucleus. Dendrites were reconstructed from serial sections extending $500 \mu \mathrm{m}$ rostral and caudal to the cell body. Two sphincter motoneurons (left side) were labelled by retrograde axonal transport following injections of cholera toxinHRP into the external urethral sphincter. Although the dendritic distributions are incomplete, they show prominent dendritic projections of one cell to lamina $\mathrm{X}$ around the central canal and projections of another cell to the intermediolateral region. Right and left sides are at slightly different rostrocaudal levels. Calibration represents $500 \mu \mathrm{m}$

\section{Interneurons}

Tract tracing using viruses which cross synapses has been very effective in identifying spinal interneuronal as well as brain pathways involved in the control of the lower urinary tract. ${ }^{33-37}$ As shown in Figure 8, interneurons retrogradely labelled by injection of pseudorabies virus into the urinary bladder of the rat are located in restricted regions of the spinal cord including the area surrounding the autonomic nucleus, the dorsal commissure and the superficial laminae of the dorsal horn. Interneuronal locations overlap in many respects with the dendritic distribution of the efferent neurons. A similar distribution of labelled interneurons has been noted following injections of virus into the urethra ${ }^{35}$ or the external urethral sphincter ${ }^{37}$ indicating a prominent overlap of the interneuronal pathways controlling the various target organs of the lower urinary tract.

\section{Afferent projections in the spinal cord}

Afferent pathways from the LUT project to discrete regions of the dorsal horn that contain the interneurons as well as the soma and/or dendrites of efferent neurons innervating the LUT. Pelvic nerve afferent pathways from the urinary bladder of the cat ${ }^{1,19}$ and rat $^{26}$ project into Lissauer's tract at the apex of the dorsal horn and then pass rostrocaudally giving off collaterals that extend laterally and medially through the superficial layer of the dorsal horn (lamina I) into the deeper layers (laminae V-VII and X) at the base of the dorsal horn (Figure 2A). The lateral pathway which is the most prominent projection terminates in the region of the sacral parasympathetic nucleus (SPN) and also sends some axons to the dorsal commissure (Figure 2A). Bladder afferents have not been detected in the center of the dorsal horn (laminae III-IV) or in the ventral horn.

The spinal neurons involved in processing afferent input from the lower urinary tract have been identified by the expression of the immediate early gene, $c$-fos (Figure 2B) ${ }^{21,38}$ The protein product of the $c$-fos gene can be detected immunocytochemically in the nuclei of neurons within 30-60 min following synaptic activation. In the rat noxious ${ }^{21}$ or non-noxious ${ }^{38}$ stimulation of the bladder and urethra as well as electrical stimulation of the pelvic nerves increased the levels of fos protein primarily in the dorsal commissure and in the area of the sacral parasympathetic nucleus, the major sites of termination of afferents from the lower urinary tract (Figure 2A).

\section{Storage reflexes \\ Sympathetic pathways}

Studies in animals indicate that sympathetic input to the lower urinary tract is tonically active during bladder filling. ${ }^{1,3}$ Surgical or pharmacologic blockade of the sympathetic pathways can reduce urethral resistance, reduce bladder capacity, reduce bladder wall compliance and increase the frequency and amplitude of bladder contractions. ${ }^{1}$

Sympathetic firing is initiated at least in part by a sacrolumbar intersegmental spinal reflex pathway which is triggered by vesical afferent activity in the pelvic nerves (Figure 5).,3 This vesicosympathetic reflex represents a negative feedback mechanism whereby an increase in bladder pressure triggers an increase in inhibitory input to the bladder thus allowing the bladder to accommodate larger volumes of urine.

\section{Somatic efferent pathways to the urethral sphincter}

The reflex control of the striated urethral sphincter is similar to the control of the sympathetic outflow to the lower urinary tract (Figure 5). During bladder filling pudendal motoneurons are activated by vesical afferent input, whereas during micturition the motoneurons are reciprocally inhibited. The inhibition is dependent in part on supraspinal mechanisms since in chronic spinal animals and in paraplegic patients it is weak or absent. In spinal injured patients the uninhibited spinal vesicosphincter excitatory reflex pathway commonly initiates a striated sphincter contraction in concert with a contraction of the bladder (bladder-sphincter dyssynergia) (Figure 4C) ${ }^{4-6}$ This reflex interferes with bladder emptying. 
Voiding reflexes

Micturition is mediated by activation of the sacral parasympathetic efferent pathway to the bladder and reciprocal inhibition of the somatic pathway to the urethral sphincter (Table 2; Figure 4B). Studies in cats using brain lesioning techniques revealed that neurons in the brainstem at the level of the inferior colliculus have an essential role in the control of the parasympathetic component of micturition (Figure 6). Removal of areas of the brain above the inferior colliculus by intercollicular decerebration usually facilitates micturition by elimination of inhibitory inputs from more rostral centers. ${ }^{1,5,27}$ However, transections at any point below the colliculi abolish micturition. Bilateral lesions in the rostral pons in the region of the locus coeruleus in cats or the lateral dorsal tegmental nucleus in rats abolishes micturition, whereas electrical or chemical stimulation at these sites triggers bladder contractions and micturition. ${ }^{1,3,27,39-41}$ These observations led to the concept of a spinobulbospinal micturition reflex pathway that passes through a center in the rostral brainstem (the pontine micturition center, PMC) (Figure 6). The pathway functions as 'on-off' switch (Figure 3) which is activated by a critical level of afferent activity arising from tension receptors in the bladder and is in turn modulated by inhibitory and excitatory influences from areas of the brain rostral to the pons (eg diencephalon and cerebral cortex) (Figure 6).

\section{Spinobulbospinal micturition reflex pathway}

Electrophysiological studies in cats and rats have confirmed that the parasympathetic efferent outflow to the urinary bladder is activated by a long latency supraspinal reflex pathway..$^{1,3,42-44}$ In cats recordings from sacral parasympathetic preganglionic neurons innervating the urinary bladder show that reflex firing occurs with a long latency $(65-100 \mathrm{~ms})$ following stimulation of myelinated ( $\mathrm{A} \delta$ ) vesical afferents in the pelvic nerve. ${ }^{1,3,44}$ Afferent stimulation also evokes negative field potentials in the rostral pons at latencies of 30-40 ms; whereas electrical stimulation in the pons excites sacral preganglionic neurons at latencies of $45-60 \mathrm{~ms}$. The sum of the latencies for the spinobulbar and bulbospinal components of the reflex pathway approximate the latency for the entire reflex.

Recent experiments have also provided information regarding the transmitter in the descending limb of the micturition reflex pathway. ${ }^{1}$ Glutamic acid has attracted most interest since it is the major excitatory transmitter in the central nervous system. Experiments in rats indicate that glutamatergic transmission in the spinal cord is essential for bladder and urethral sphincter reflexes and for the spinal processing of afferent input from the urinary bladder. ${ }^{45-48}$ Both NMDA and non-NMDA glutamatergic receptors have been implicated in transmission between the brain micturition center and the spinal preganglionic neurons. These receptors also mediate excitatory transmission between interneurons and preganglionic neurons. ${ }^{49}$ Thus, glutamate is likely to be involved at various sites in the micturition reflex pathway.

\section{Pontine micturition center (PMC)}

Physiological and anatomical experiments have provided substantial support for the concept that neuronal circuitry in the PMC functions as a switch in the micturition reflex pathway. The switch seems to regulate bladder capacity and also coordinates the activity of the bladder and of the external urethral sphincter. ${ }^{1,39}$ Electrical or chemical stimulation in the PMC of the rat, cat and dog induces: (1) a suppression of urethral sphincter EMG, (2) firing of sacral preganglionic neurons, (3) bladder contractions and (4) release of urine. ${ }^{1.35}, 50$ On the other hand, microinjections of putative inhibitory transmitters into the PMC of the cat can increase the volume threshold for inducing micturition and in high doses completely block reflex voiding indicating that synapses in this region are important for regulating the set point for reflex voiding and also are an essential link in the reflex pathway. ${ }^{39}$ In addition administration of antagonists for certain inhibitory transmitters (eg the GABA-antagonist, bicuculline or the opioid antagonist, naloxone) can reduce the micturition volume threshold indicating that the setpoint is under tonic inhibitory modulation.

Virus tracing studies in the rat have revealed extensive labelling in the PMC (Figure 8) following injections of virus into the bladder, urethra and the external urethral sphincter. ${ }^{33-37}$ These data are consistent with the view that neurons in this region coordinate the activity of all the major organs involved in voiding.

\section{Recovery of lower urinary tract function following spinal cord injury}

Spinal cord injury rostral to the lumbosacral level eliminates voluntary and supraspinal control of voiding, leading initially to an areflexic bladder and complete urinary retention followed by a slow development of automatic micturition and bladder hyperactivity mediated by spinal pathways. ${ }^{1,4-6,44,51-53}$ However, voiding is commonly inefficient due to simultaneous contractions of the bladder and the urethral sphincter (bladder-sphincter dyssynergia).

\section{Reorganization of reflex pathways}

Electrophysiological studies in rats and cats have shown that the reflex pathways in intact and chronic animals are markedly different. In both species, the central delay for the micturition reflex in chronic spinal animals is considerably shorter $(<5 \mathrm{~ms}$ in rats; $15-40 \mathrm{~ms}$ in cats) than in intact animals $(60-75 \mathrm{~ms}) \cdot{ }^{1,3,42,44}$ In addition, in chronic spinal cats the afferent limb of the micturition reflex consists of unmyelinated (C-fiber) afferents, whereas in intact cats it consists of myelinated (A $\delta$ ) afferents (Figure 6). ${ }^{23}$ This was demonstrated with electrophysiological recording and also by administering capsaicin, ${ }^{23}$ a 

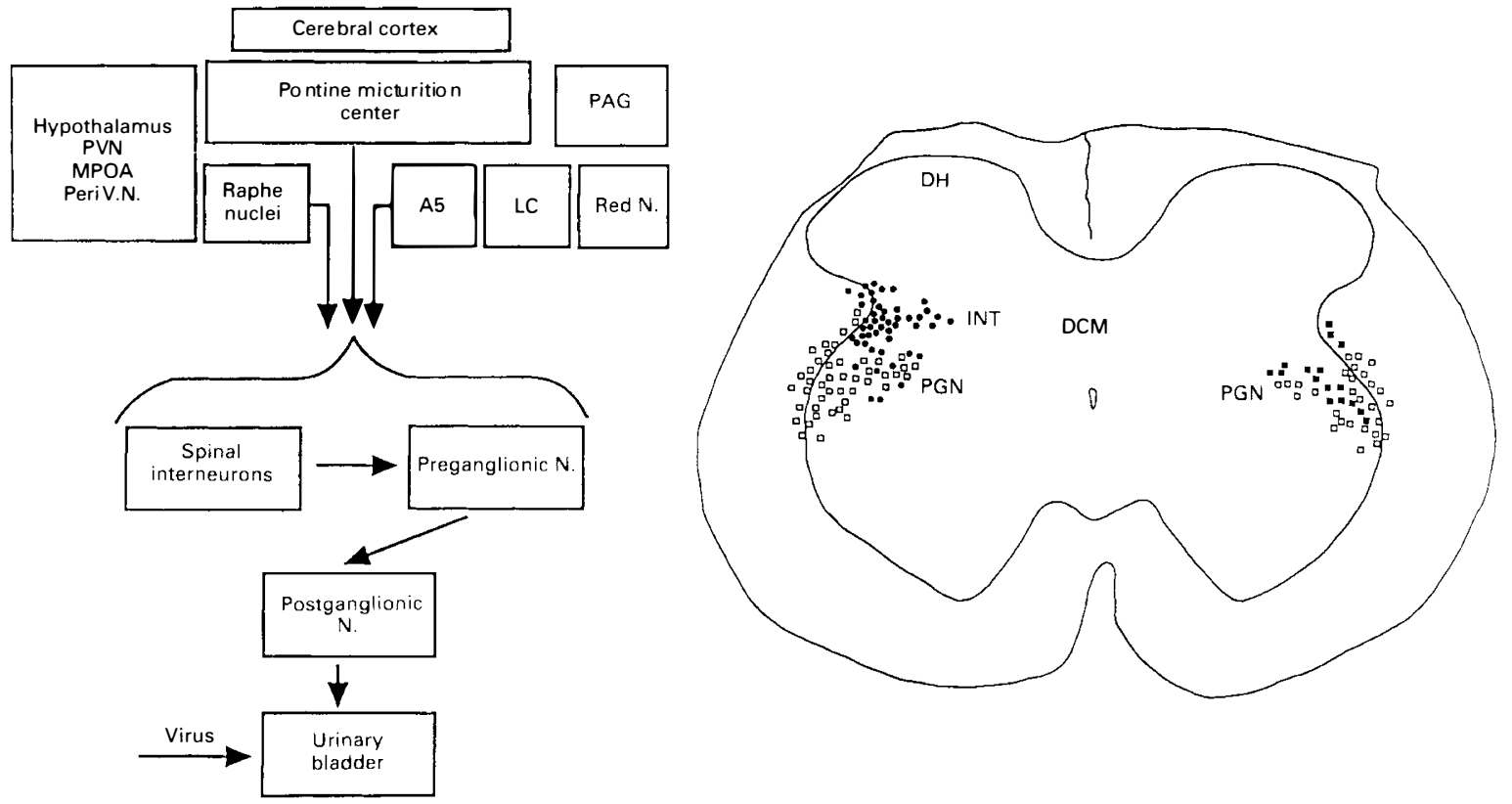

Figure 8 Transneuronal virus tracing of the central pathways controlling the urinary bladder of the rat. Injection of pseudorabies virus into the wall of the urinary bladder leads to retrograde transport of virus and sequential infection of postganglionic neurons, preganglionic neurons and then various central neural circuits synaptically linked to the preganglionic neurons. At long survival times virus can be detected with immunocytochemical techniques in neurons at specific sites throughout the spinal cord and brain extending to the pontine micturition center in the pons (ie Barrington's nucleus or the laterodorsal tegmental nucleus) and to the cerebral cortex. Other sites in the brain labeled by virus are: (1) the paraventricular nucleus (PVN), medial preoptic area (MPOA) and periventricular nucleus (Peri V.N.) of the hypothalamus, (2) periaqueductal gray (PAG), (3) locus coeruleus (LC) and subcoeruleus, (4) red nucleus (RN), (5) medullary raphe nucleus and (6) the noradrenergic cell group designated A5. L6 spinal cord section showing on the left side the distribution of virus labelled parasympathetic preganglionic neurons ( $\square$ ) and interneurons ( ) in the region of the parasympathetic nucleus $72 \mathrm{~h}$ after injection of the virus into the bladder. Interneurons in the dorsal commissure and the superficial laminae of the dorsal horn are not shown. The left side shows the entire population of preganglionic neurons (PGN) labeled by axonal tracing with the fluorescent dye fluorogold, injected into the pelvic ganglia. The right side shows the distribution of virus-labeled bladder PGN (ם) among the entire population of PGN ( $\square$ ). Composite diagram of neurons in 12 spinal sections $(42 \mu \mathrm{m})$

neurotoxin which is known to disrupt the function of C-fiber afferents. ${ }^{17}$ In normal cats, capsaicin injected systemically in large doses $(30-45 \mathrm{mg}$, s.c.) did not block reflex contractions of the bladder or the A $\delta$-fiber evoked bladder reflex. However in chronic spinal cats (3-6 weeks after spinal transection) capsaicin $(20-30 \mathrm{mg} / \mathrm{kg}$, s.c.) completely blocked the rhythmic bladder contractions induced by bladder distension and blocked the C-fiber-evoked reflex firing recorded on bladder postganglionic nerves. ${ }^{23,44}$ Thus, there seems to be a considerable reorganization of reflex connections in the spinal cord following the interruption of descending pathways from the brain. C-fiber afferent-evoked reflexes which are weak and occur in only $60 \%$ of cats with an intact neuraxis ${ }^{44}$ are facilitated; whereas $\mathrm{A} \delta$ afferent-evoked reflexes are completely eliminated in chronic spinal animals. These data indicate that two distinct central pathways (supraspinal and spinal) utilizing different peripheral afferent limbs (A and $\mathrm{C}$ fiber) can mediate detrusor to detrusor reflexes in the cat (Figure 6). The properties of the peripheral C-fiber afferent receptors also appear to be changed in the spinal injured cat. As mentioned above, C-fiber bladder afferents in the cat usually do not respond to bladder distension (ie silent C-fibers). ${ }^{15}$ However, in chronic spinal cats bladder distension initiates automatic micturition by activating C-fiber afferent neurons. ${ }^{23}$ Thus, spinal injury must change the properties of these afferent receptors in the bladder.

Other reflexes that appear following spinal cord injury also may be mediated by $\mathrm{C}$-fiber afferents. For example, it is known that instillation of cold water into the bladder of patients with upper motoneuron lesions induces reflex voiding (the Bors Ice Water Test). ${ }^{6}$ This reflex does not occur in normal patients. Recently, it has been shown in the cat that $\mathrm{C}$-fiber bladder afferents are responsible for cold-induced bladder reflexes. ${ }^{20}$

Arterial pressor responses induced by bladder distension occur in spinal injured patients and animals. ${ }^{4,5,54}$ In normal and spinal injured rats the increase in blood pressure induced by isometric bladder contractions or distension is suppressed by capsaicin treatment. ${ }^{22,54}$ This suggests that $\mathrm{C}$-fiber afferents mediate bladdervascular reflexes in this species. Similar afferents may be responsible for autonomic dysreflexia, in tetraplegic patients.

Capsaicin has also been evaluated clinically for the treatment of various types of neurogenic disorders of 
the lower urinary tract. When administered intravesically in concentrations between $100 \mathrm{uM}$ and $2 \mathrm{mM}$ capsaicin increases bladder capacity and reduces irritative symptoms in patients with hypersensitive blad$\operatorname{ders}^{17,55}$ and increases bladder capacity and reduces the frequency of incontinence in patients with multiple sclerosis. ${ }^{56,57}$ The effects of high concentrations of capasaicin in multiple sclerosis patients persisted for weeks to months after treatment.

In preliminary studies on a small population of spinal cord injured patients with detrusor hyperreflexia and autonomic dysreflexia, intravesical capsaicin treatment increased bladder capacity, depressed the micturition contraction pressure, decreased autonomic dysreflexia, decreased urge incontinence and blocked the bladder cooling reflex. ${ }^{58,59}$ These observations suggest that capsaicin-sensitive, C-fiber bladder afferents are involved in several pathological conditions associated with neurogenic bladder hyperactivity.

\section{Mechanisms of reflex plasticity following spinal cord injury}

The recovery of automatic micturition and $\mathrm{C}$-fiber afferent-evoked bladder reflexes in paraplegic cats may be dependent on multiple mechanisms: (1) elimination of bulbospinal inhibitory pathways, (2) strengthening of existing synapses or formation of new synaptic connections due to axonal sprouting in the spinal cord, (3) changes in synthesis, release, or actions of neurotransmitters, (4) alterations in afferent input from peripheral organs. For example, vasoactive intestinal polypeptide (VIP) immunoreactivity which is a marker for C-fiber afferents ${ }^{18,19,23,60,61}$ and for a proportion of the bladder afferent terminals in the sacral spinal cord of the cat ${ }^{18,23}$ is distributed over a wider area of the lateral dorsal horn in paraplegic cats. ${ }^{62}$ This is consistent with the concept of afferent axonal sprouting following spinal cord injury. In addition, the effects of intrathecal administration of VIP on bladder function are changed in paraplegic cats. In normal cats VIP inhibits bladder reflexes; whereas in paraplegic cats small doses of VIP facilitate reflexes (Figure 9). ${ }^{23}$ These findings suggest that the action of a putative $\mathrm{C}$-fiber afferent transmitter is changed in concert with the emergence of $\mathrm{C}$-fiber reflexes.

Although bladder reflexes recover in paraplegic patients the bladder does not empty efficiently due to uninhibited sphincter contractions (ie bladdersphincter dyssynergia). ${ }^{4-6}$ As shown in Figure $4 \mathrm{C}$ when the bladder contracts reflexly in the paraplegic patient the sphincter also contracts producing a functional outlet obstruction and a large volume of residual urine. Thus viscerosomatic coordination in the lower urinary tract appears to depend on control mechanisms located in the brain.

The failure of bladder sphincter coordination may also lead to changes in spinal reflex pathways. It has been speculated ${ }^{23,63}$ that bladder-sphincter dyssynergia and outlet obstruction in paraplegic animals could alter the properties of bladder afferent pathways and reflex
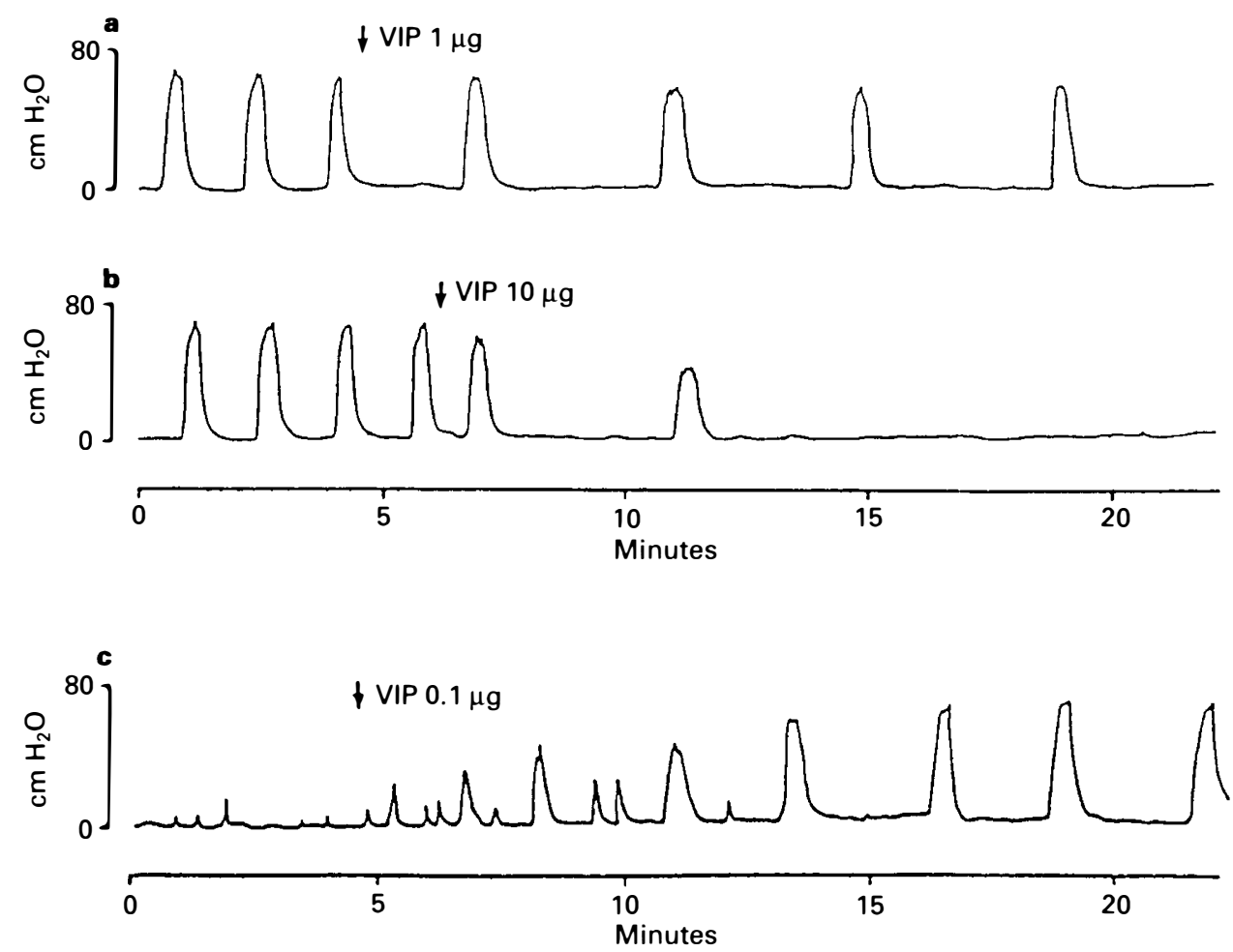

Figure 9 Effects of intrathecal administration of VIP on rhythmic bladder activity. In normal cats, large doses of VIP (1 to $10 \mu \mathrm{g}$ ) inhibit bladder activity (A and B), whereas in chronic spinal cats smaller doses of VIP (0.1 to $1 \mu \mathrm{g})$ facilitate bladder activity (C). Reproduced from de Groat WC et al, $1990^{23}$ with permission 
mechanisms. This has been demonstrated in chronic spinal rats 4-6 weeks after transection of the spinal cord. ${ }^{64}$ In these animals reflex voiding had developed; however voiding was inefficient (30-fold increase in residual volume) due to tonic activity of the urethral sphincter. ${ }^{24,51}$ The bladder was markedly enlarged (5-fold increase in weight) (Figure 10) and showed prominent uninhibited contractions during cystometrograms. Systemic capsaicin administration eliminated the uninhibited contractions but did not block the micturition reflex. ${ }^{24}$ Anatomical tracing studies revealed that the afferent neurons innervating the bladder were markedly increased in size (approximately $50 \%$ increase) (Figure 10) in the chronic spinal animals compared to neurons in normal control animals. ${ }^{64}$ The increase in size of afferent neurons could be associated with sprouting of afferent axons in the bladder to innervate the larger target tissue. A larger cell body might be necessary to support a larger afferent terminal field (Figure 10). This morphological change in bladder afferent neurons is consistent with the hypothesis presented above that plasticity in the afferent limb of the micturition reflex might contribute to the recovery of voiding function in paraplegic animals.

The signal for afferent neuron plasticity after spinal injury has been explored using several experimental approaches. One approach was to perform a urinary
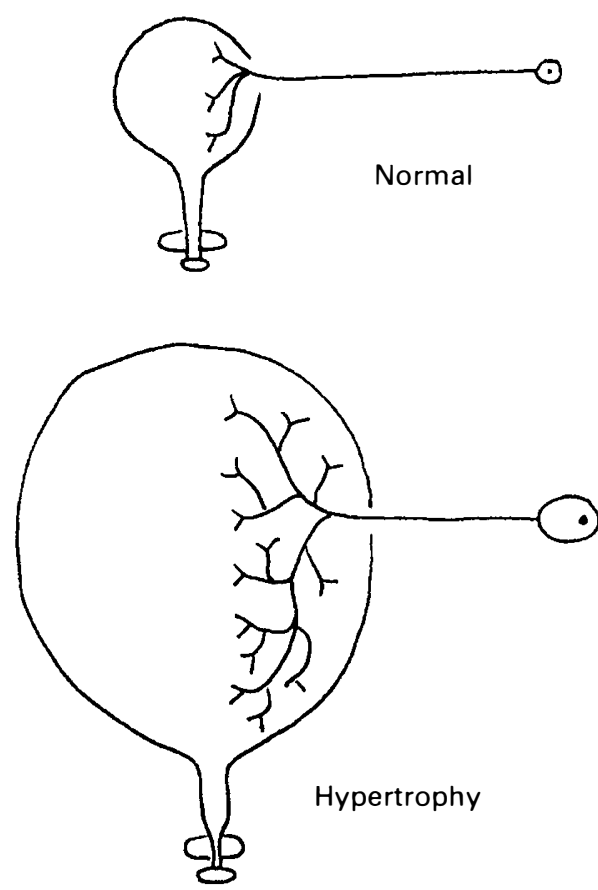

Figure 10 Changes in the innervation of the urinary bladder of the rat in response to bladder hypertrophy. When the bladder smooth muscle mass increases following urethral obstruction, the neurons innervating the bladder also increase in size. This has been detected as an increase in the cross sectional area of perikarya in sensory and autonomic ganglia. It also seems likely that axons in the bladder will sprout to maintain a normal density of innervation in the hypertrophied organ diversion procedure to prevent bladder distension and hypertrophy in the paraplegic animals. ${ }^{52,64}$ This prevented the afferent neuron hypertrophy suggesting that factors released in the hypertrophied bladder were responsible for the neural changes. A second approach evaluated the neural changes induced by outlet obstruction due to partial urethral ligation. ${ }^{26,65,66}$ Urethral ligation increased bladder work and induced bladder hypertrophy but did not eliminate the normal supraspinal control of the voiding. ${ }^{65}$ Outlet obstruction of 4-6 weeks duration induced hypertrophy of bladder afferent (45\% increase in size) and efferent neurons $(100 \%$ increase $) .{ }^{26,66}$ This was accompanied by increased levels of nerve growth factor (NGF) in the bladder, ${ }^{67}$ as well as an expansion of the bladder afferent terminals in the cord and facilitation of the spinal micturition reflex. ${ }^{26,65}$ Autoimmunization of rats against NGF reduced the hypertrophy of efferent neurons indicating that changes in the levels of trophic factors in the bladder can have a significant influence on the neurons innervating the bladder. ${ }^{67}$ Thus it is possible that spinal reflex mechanisms are affected indirectly by changes in organ functions which occur following spinal injury (Figures 11, 12).

Electrical recordings from bladder afferent neurons have revealed that the physiological properties of the

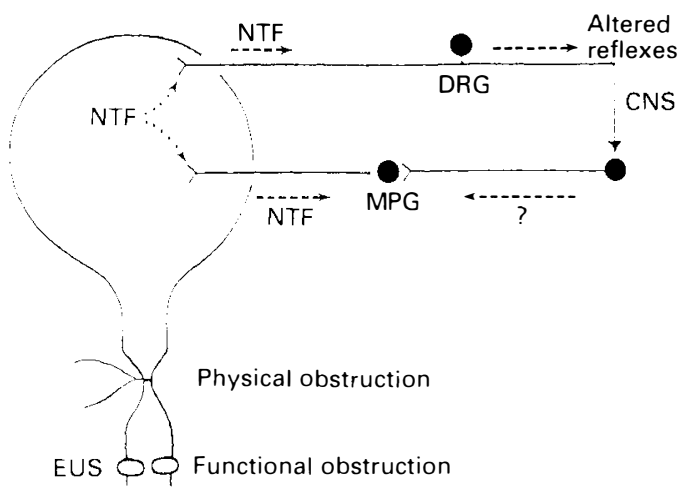

Figure 11 Diagram indicating the possible role of neurotrophic factors (NTF) in the neuroplasticity in afferent and efferent pathways to the urinary bladder of the rat following spinal cord injury or partial urethral obstruction. Increased urethral resistance induced by functional urethral obstruction caused by enhanced external urethral sphincter (EUS) activity in paraplegic animals or by physical obstruction due to partial urethral ligation induces bladder hypertrophy and increased levels of NTF in the bladder. In the physically obstructed animals NTF taken up by afferent and efferent terminals (dashed arrows) induces hypertrophy of bladder neurons in the major pelvic ganglion (MPG) and dorsal root ganglia (DRG) and increases the density of WGA-HRP labelled bladder afferent terminals in certain regions of the spinal cord. On the other hand, functional obstruction induces a selective increase in bladder afferent neuron size and changes the electrophysiological properties of these neurons, but does not induce hypertrophy of efferent neurons in the MPG. This raises the possibility that neural activity or trophic substances (?) released by preganglionic pathways from the spinal cord to the MPG negates the influence of peripheral neurotrophic factors 


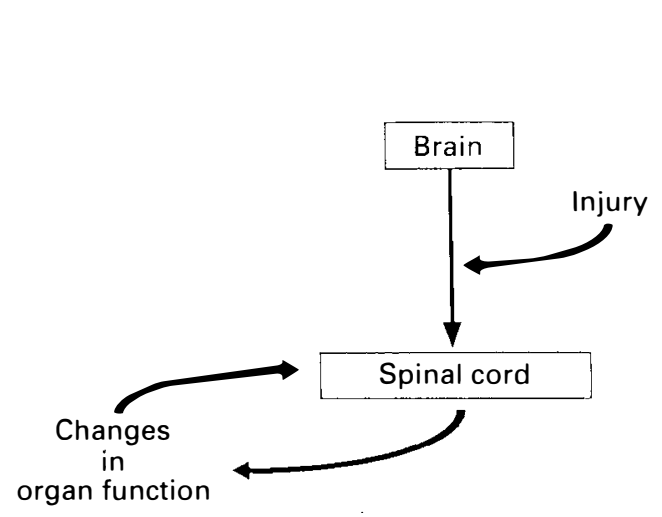

Figure 12 Diagram indicating an indirect mechanism that might contribute to the changes in reflex circuitry in segments of spinal cord caudal to the level of spinal injury. Interruption of descending pathways from the brain to the spinal cord can lead to changes in autonomic and somatic motor outflow to effector organs and thereby alter organ function. Experimental studies in spinal injured animals indicate that changes in lower urinary function can alter the morphological and physiological properties of afferent neurons innervating the urinary bladder. It is speculated that changes in afferent input to the spinal cord in paraplegic animals may have a significant influence on the reorganization of spinal reflex circuitry that occurs following spinal cord injury

neurons are also altered after spinal cord injury. Whole cell patch clamp recordings were performed on acutely dissociated lumbosacral dorsal root ganglion cells from normal and chronic spinal rats. ${ }^{63,68-70}$ Cells were identified as bladder neurons by retrograde axonal transport of fluorescent dyes from the bladder. Changes in $\mathrm{Na}+$ and $\mathrm{K}+$ currents were noted after cord injury. A large majority $(80 \%)$ of bladder afferent neurons from normal animals exhibited high threshold $\mathrm{Na}+$ currents that were resistant to tetrodotoxin (TTX) and low threshold $\mathrm{K}+$ currents (A-type) that were activated at voltages between -60 and $-50 \mathrm{mV}$. Due to this combination of ion channels the neurons were relatively inexcitable. However in chronic spinal animals with bladder hypertrophy the majority $(75 \%)$ of afferent neurons exhibited low threshold TTX-sensitive $\mathrm{Na}+$ currents and an absence of A-type $\mathrm{K}+$ currents. These alterations in ion channels increased the excitability of the afferent neurons. Similar alterations in electrical excitability at afferent receptors in the bladder could account for the apparent increased sensitivity of silent C-fiber afferents to bladder distension in paraplegic cats. Thus, the changes in synthesis and/or release of trophic factors by target organs in the lower urinary tract appear to alter the properties of bladder afferent pathways. These changes may have an impact on the reorganization of central synaptic mechanisms and the recovery of bladder function following spinal cord injury.

\section{Conclusions}

The lower urinary tract has two main functions: storage and periodic elimination of urine. These functions are regulated by a complex neural control system located in the brain and spinal cord. This control system performs like a simple switching circuit to maintain a reciprocal relationship between the reservoir (bladder) and outlet components (urethra and urethral sphincter) of the urinary tract. Spinal cord injury disrupts voluntary control and the normal reflex pathways that coordinate bladder and sphincter function. Studies in animals indicate that recovery of bladder function following spinal injury is dependent upon the reorganization of reflex pathways in both the peripheral and central nervous system. Part of this reorganization may be influenced by neural-target organ interactions (Figure 12) that are mediated by neurotrophic factors released by the peripheral organs.

\section{References}

1 de Groat WC, Booth AM, Yoshimura N. Neurophysiology of micturition and its modification in animal models of human disease. In: Maggi CA (ed). The Autonomic Nervous System, Vol. 3, Nervous Control of the Urogenital System. 1st edn. Harwood Academic Publishers: London; 1993, pp 227-290.

2 de Groat WC, Booth AM. Synaptic transmission in pelvic ganglia. In: Maggi CA (ed). The Autonomic Nervous System, Vol. 3, Nervous Control of the Urogenital System. 1st edn. Harwood Academic Publishers: London; 1993, pp 291-347.

3 de Groat WC. Nervous control of the urinary bladder of the cat. Brain Res 1975, 87: 201-211.

4 Van Arsdalen K, Wein AJ. Physiology of micturition and continence. In: Krane RJ, Siroky M (eds). Clinical Neuro-Urology. 2nd edn. Little Brown \& Company: New York, 1991: 25-82.

5 Torrens M, Morrison JFB. The Physiology of the Lower Urinary Tract. Springer-Verlag: Berlin, 1987.

6 Bors E, Comarr AE. Neurological Urology, Physiology of Micturition, its Neurological Disorders and Sequelae. University Park Press: Baltimore, 1971.

7 de Groat WC, Steers WD. Autonomic regulation of the urinary bladder and sex organs. In: Loewy AD, Spyer KM, (eds). Central Regulation of Autonomic Functions. 1st edn. Oxford University Press: Oxford, 1990, pp 310-333.

8 de Groat WC. Neural control of urinary bladder and sexual organs. In: Bannister R, Mathias CJ, (eds). Autonomic Failure. 3rd edn. Oxford University Press: Oxford, 1992; pp 129-159.

9 Andersson K-E. Pharmacology of lower urinary tract smooth muscles and penile erectile tissues. Pharmacol Rev 1993; 45: 253-308.

10 Somogyi GT, de Groat WC. Evidence of inhibitory nicotinic and facilitatory muscarinic receptors in cholinergic nerve terminals of the rat urinary bladder. J Auton Nerv Syst 1992; 37: $89-97$.

11 Somogyi GT, Tanowitz M, de Groat WC. M-1 muscarinic receptor mediated facilitation of acetylcholine release in the rat urinary bladder but not in the heart. J Physiol (Lond) 1994; 480: 81-89.

12 Tran LV, Somogyi GT, de Groat WC. Inhibitory effects of neuropeptide $\mathrm{Y}$ on cholinergic and adrenergic transmission in the rat urinary bladder and urethra. Am J Physiol 1994; 266: R1411-R1417.

13 Bennett BC, Roppolo JR, Kruse MN, de Groat WC. Neural control of urethral smooth and striated muscle activity in vivo: role of nitric oxide. J Urol 1995; 153: 2004-2009.

14 Jänig W, Morrison JFB. Functional properties of spinal visceral afferents supplying abdominal and pelvic organs, with special emphasis on visceral nociception. Prog Brain Res 1986; 67: $87-114$

15 Häbler HJ, Jänig W, Koltzenburg M. Activation of unmyelinated afferent fibres by mechanical stimuli and inflammation of the urinary bladder in the cat. J Physiol (Lond) 1990; 425: $545-562$.

16 Jänig W, Koltzenburg M. Pain arising from the urogenital tract. 
In: Maggi CA (ed). The Autonomic Nervous System, Vol. 3, Nervous Control of the Urogenital System. 1st edn. Harwood Academic Publishers: London, 1993, pp 525-578.

17 Maggi CA. The dual, sensory and efferent function of the capsaicin-sensitive primary sensory nerves in the bladder and urethra. In: Maggi CA, (ed). The Autonomic Nervous System, Vol. 3, Nervous Control of the Urogenital System. 1st edn. Harwood Academic Publishers: London, 1993; pp 383-422.

18 de Groat WC. Neuropeptides in pelvic afferent pathways. Experientia 1987; 43: 801-812.

19 de Groat WC. Spinal cord projections and neuropeptides in visceral afferent neurons. Prog Brain Res 1986; 67: 165-187.

20 Fall M, Lindström S, Mazieres L. A bladder-to-bladder cooling reflex in the cat. J Physiol (Lond) 1990; 427: 281-300.

21 Birder LA, de Groat WC. Increased $c$-fos expression in spinal neurons after chemical irritation of the lower urinary tract of the rat. J Neurosci 1992; 12: 4878-4889.

22 Cheng C-L, Ma C-P, de Groat WC. The effects of capsaicin on micturition and associated reflexes in the rat. Am J Physiol 1993; 265: R132-R648.

23 de Groat WC et al. Mechanisms underlying the recovery of urinary bladder function following spinal cord injury. $J$ Auton Nerv Syst 1990; 30 (Suppl): S71-S77.

24 Cheng C-L, Ma C-P, de Groat WC. Effect of capsaicin on micturition and associated reflexes in chronic spinal rats. Brain Res (in press).

25 Keast JR, de Groat WC. Segmental distribution and peptide content of primary afferent neurons innervating the urogenital organs and colon of male rats. J Comp Neurol 1992; 319: $615-623$.

26 Steers WD et al. Alterations in afferent pathways from the urinary bladder of the rat in response to partial urethral obstruction. J Comp Neurol 1991; 310: 401-410.

27 Kuru M. Nervous control of micturition. Physiol Rev 1991; 45: 425-494.

28 Morgan CW, de Groat WC, Felkins LA, Zhang SJ. Intracellular injection of neurobiotin or horseradish peroxidase reveals separate types of preganglionic neurons in the sacral parasympathetic nucleus of the cat. J Comp Neurol 1993; 331: 161-182.

29 Morgan CW, de Groat WC, Felkins LA, Zhang SJ. Axon collaterals indicate broad intraspinal role for sacral preganglionic neurons. Proc Natl Acad Sci USA 1991; 88: 6888-6892.

30 Roppolo JR, Nadelhaft I, de Groat WC. The organization of pudendal motoneurons and primary afferent projections in the spinal cord of the rhesus monkey revealed by horseradish peroxidase. J Comp Neurol 1985; 234: 475-488.

31 Thor KB et al. Organization of afferent and efferent pathways in the pudendal nerve of the female cat. J Comp Neurol 1989; 288: 263-279.

32 Sasaki M. Morphological analysis of external urethral and external anal sphincter motoneurones of cat. J Comp Neurol 1994; 349: 269-287.

33 de Groat WC, Roppolo JR, Yoshimura N, Sugaya K. Neural control of the urinary bladder and colon. In: Taché Y, Wingate $\mathrm{D}$, Burks T, (eds). Proceedings of the Second International Symposium on Brain-Gut Interactions. CRC Press: Boca Raton, FL, 1993, pp 167-190.

34 Nadelhaft I, Vera PL, Card JP, Miselis RR. Central nervous system neurons labelled following the injection of pseudorabies virus into the rat urinary bladder. Neurosci. Lett 1992; 143: 271-274.

35 Vizzard MA et al. Transneuronal labelling of neurons in the adult rat brainstem and spinal cord after injection of pseudorabies virus into the urethra. J Comp Neurol 1995; 355: 629-640.

36 de Groat WC et al. Identification of bladder preganglionic (PGN) and interneurons (INTs) in the L6-S1 spinal cord of the adult rat using pseudorabies (PRV) and fluorogold (FG) dye tracing techniques. Soc Neurosci Abstr 1994; 20 : 114.

37 Erickson VL et al. The distribution of pseudorabies virus (PRV) labeled neurons in the central nervous system (CNS) following injection into external urethral sphincter (EUS). Soc Neurosci Abstr 1994; 20: 115.

38 Birder LA, de Groat WC. Induction of $c$-fos gene expression in spinal neurons in the rat by nociceptive and non-nociceptive stimulation of the lower urinary tract. Am J Physiol 1993; 265: R643-R648.

39 Mallory BS, Roppolo JR, de Groat WC. Pharmacological modulation of the pontine micturition center. Brain Res 1991; 546: $310-320$.

40 Noto H, Roppolo JR, Steers WD, de Groat WC. Excitatory and inhibitory influences on bladder activity elicited by electrical stimulation in the pontine micturition center in rat. Brain Res 1989; 492: 99-115.

41 Chen SY et al. Glutamate activation of neurons in cardiovascular reactive areas of the cat brain stem affects urinary bladder motility. Am J Physiol 1993; 265: F520-F529.

42 Mallory B, Steers WD, de Groat WC. Electrophysiological study of micturition reflexes in rats. Am J Physiol 1989; 257: R410-R421.

43 de Groat WC, Ryall RW. Reflexes to sacral parasympathetic neurones concerned with micturition in the cat. $J$ Physiol (Lond) 1969; 200: 87-108.

44 de Groat WC et al. Organization of the sacral parasympathetic reflex pathways to the urinary bladder and large intestine. J Auton Nerv Syst 1981; 3: 135-160.

45 Yoshiyama M, Roppolo JR, de Groat WC. Effects of MK-801 on the micturition reflex in the rat: possible sites of action. J Pharmacol Exp Ther 1993; 265: 844-850.

46 Yoshiyama M, Roppolo JR, de Groat WC. Interactions between glutamatergic and monoaminergic systems controlling the micturition reflex in the urethane-anesthetized rat. Brain Res 1994; 639: 300-308.

47 Matsumoto G, Hisamitsu T, de Groat WC. Role of glutamate and NMDA receptors in the descending limb of the spinobulbospinal micturition reflex pathway of the rat. Neurosci Lett 1995; 183: $58-61$

48 Matsumoto G, Hisamitsu T, de Groat WC. Non-NMDA glutamatergic excitatory transmission in the descending limb of the spinobulbospinal micturition reflex pathway of the rat. Brain Res (in press)

49 Araki I, de Groat WC. Patch clamp and morphological analysis of synaptic transmission in the lumbosacral parasympathetic nucleus (SPN) of neonatal rats. Soc Neurosci Abstr 1994; 20 : 115.

50 Holstege G, Griffiths D, De Wall H, Dalm E. Anatomical and physiological observations on supraspinal control of bladder and urethral sphincter muscles in the cat J Comp Neurol 1986; 250: 449-461.

51 Kruse MN, Belton AL, de Groat WC. Changes in bladder and external urethral sphincter function after spinal cord injury in the rat. Am J Physiol 1993; 264: R1157-R1163.

52 Kruse MN, Bennett BC, de Groat WC. Effect of urinary diversion on the recovery of micturition reflexes after spinal cord injury in the rat. J Urol 1994; 151: 1088-1091.

53 Kruse MN, de Groat WC. Consequences of spinal cord injury during the neonatal period on micturition reflexes in the rat. Exp Neurol 1994; 125: 87-92.

54 Giuliani S, Maggi CA, Meli A. Capsaicin-sensitive afferents in the rat urinary bladder activate a spinal sympathetic cardiovascular reflex. Naunyn-Schmiedebergs Arch Pharmacol 1988; 338: 411-416.

55 Maggi CA et al. Cystometric evidence that capsaicin-sensitive nerves modulate the afferent branch of micturition reflex in humans. J Urol 1989; 142: 150-154.

56 Fowler CJ et al. Intravesical capsaicin for neurogenic bladder dysfunction. Lancet 1992; 339: 1239.

57 Fowler CJ et al. Intravesical capsaicin for treatment of detrusor hyperreflexia. J Neurol Neurosurg Psychiatry 1994; 57: 169-173.

58 Geirsson G, Fall M, Sullivan L. Effect of intravesical capsaicin treatment on postraumatic spinal detrusor hyperreflexia and the bladder cooling reflex. Neurourol Urodyn 1994; 13: 346-347.

59 Chancellor MB et al. Intravesical capsaicin in neurologic imparied patients with detrusor hyperreflexia and autonomic dysreflexia: preliminary study. Intersitial Cystitis Symposium Abstracts, Sponsored by NIDDK 9-11 January, 1995. NIH: Bethesda, MD, p 115. 
60 Kawatani M, Erdman SL, de Groat WC. VIP and substance P in primary afferent pathways to the sacral spinal cord of the cat. J Comp Neurol 1985; 241: 327-347.

61 Kawatani M, Nagel J, de Groat WC. Identification of neuropeptides in pelvic and pudendal nerve afferent pathways to the sacral spinal cord of the cat. J Comp Neurol 1986; 249: $117-132$.

62 Thor K, Kawatani M, de Groat WC. Plasticity in the reflex pathways to the lower urinary tract of the cat during postnatal development and following spinal cord injury. In: Goldberger ME, Gorio A, Murray M, (eds). Development and Plasticity of the Mammalian Spinal Cord. Fidia Research Series Vol. III. 1st edn. Liviana Press: Padova, 1986, pp 65-80.

63 de Groat WC and Kruse MN. Central processing and morphological plasticity in lumbosacral afferent pathways from the lower urinary tract. In: Mayer EA, Raybould HE, (eds). Basic and Clinical Aspects of Chronic Abdominal Pain. Pain Research and Clinical Management. Elsevier Science Publishers: Amsterdam, 1993; pp 219-235.

64 Kruse MN, Bray LA, de Groat WC. Influence of spinal cord injury on the morphology of bladder afferent and efferent neurons. J Auton Nerv Syst (in press).

65 Steers WD, de Groat WC. Effect of bladder outlet obstruction on micturition reflex pathways in the rat. J Urol 1988; 140: 864-871.

66 Steers WD, Ciambotti J, Erdman S, de Groat WC. Morphological plasticity in efferent pathways to the urinary bladder of the rat following urethral obstruction. $J$ Neurosci 1990; 10: 1943-1951.

67 Steers WD et al. Nerve growth factor in the urinary bladder of the adult regulates neuronal form and function. J Clin Invest 1991; 88: 1709-1715.

68 Yoshimura N, de Groat WC. Changes in electrophysiological and pharmacological properties of rat bladder afferent neurons following spinal cord injury. J Urol 1995; 149: 340A.

69 Yoshimura N, Yoshida O, de Groat WC. Regional differences in plasticity of membrane properties of rat bladder afferent neurons following spinal cord injury. J Urol 1995; 153: 262A

70 Yoshimura N, de Groat WC. Increases of neurofilament immunoreactivity and reduction of capsaicin-sensitivity in rat bladder afferent neurons following spinal cord injury. J Urol 1994; 151: 455A. 